\title{
LOS ESPACIOS TURÍSTICOS: PRODUCCIÓN, EXPERIENCIAS E IMAGINARIOS. EL CASO DE LA ARAUCANÍA ANDINO-LACUSTRE CHILENA, 1900-19401
}

\author{
Pablo Martínez Riquelme \\ Universidad de La Frontera. Chile \\ https://orcid.org/0000-0001-9368-3506
}

\section{RESUMEN}

Los procesos de producción de espacios turísticos se expresan en sendas espacio-temporales, asociadas a una producción material, como las infraestructuras, equipamiento y conectividad, pero también en una producción inmaterial, basada en la difusión de imaginarios territoriales vinculados a la experiencia turística. Se busca analizar dicho proceso, en la Araucanía andino-lacustre chilena, entre 1900-1940, a partir de los relatos de los primeros viajeros con motivaciones turísticas a finales del siglo XIX y el rol de Estado como actor promotor de la turistificación del territorio en el sur de Chile.

Palabras clave: Espacios turísticos; sendas espacio-temporales; experiencia turística; Región de La Araucanía.

Tourist spaces: production, experiences and imagination. The case of the AndeanChilean Andean lake area of La Araucanía, 1900-1940

\section{ABSTRACT}

The processes of production of tourist spaces are expressed in space-time paths, associated with a material production, such as infrastructures, equipment and connectivity, but also in an immaterial production, based on the diffusion of territorial imaginaries linked to the tourist experience. It is sought to analyze this process, in the Chilean Andean-lacustrine

Fecha de recepción: 4 de enero de 2017

Fecha de aceptación: 12 de diciembre de 2018

Universidad de La Frontera. Departamento de Ciencias Sociales. Pontificia Universidad Católica de Chile. Programa de Doctorando en Geografía. Becado Conicyt. Dirección postal 4811230. E-mail: pablo.martinez@ ufrontera.cl

1 Trabajo realizado en el marco del Programa de Doctorado en Geografía de la Pontificia Universidad Católica de Chile (Beca Conicyt) y del Proyecto de Investigación DIUFRO DI17-0010 "Producción social de espacios turísticos. El sur andino-lacustre chileno, 1850-2010", financiado por la Dirección de Investigación de la Universidad de La Frontera. 
Araucanía, between 1900-1940, based on the account of the first travelers with tourist motivations at the end of the 19th century and the role of the State as a promoter of the touristification of the territory in the South of Chile.

Keywords: Tourist spaces; Space-time paths; Tourist experience; Araucanía region.

\section{INTRODUCCIÓN}

El turismo constituye uno de los temas emergentes para las ciencias sociales en general y para la geografía en particular. En efecto, a partir de la segunda mitad del siglo XX, asociado al incremento de las tecnologías y el aumento del tiempo libre, el turismo se ha considerado como una actividad de dimensiones espaciales, comprendiendo diversas formas de viaje, estadía y motivaciones para realizarla, transformándose en un fenómeno social, económico y espacial (Boullón, 1991). La necesidad de abordar científicamente el fenómeno turístico ha sido un desafío constante para validarla como objeto de estudio, aplicando metodologías y enfoques de investigación, pero no necesariamente llegando a construir un cuerpo teórico propio (Gibson, 2008. Hall, 2011. Ioannides, et al. 2014. Pinassi y Ercolani, 2015). Para contribuir al conocimiento geográfico del turismo, se propone en este documento que la "producción del espacio turístico" es un complejo proceso cruzado por intereses, relaciones de poder, prácticas materiales y espaciales, representaciones espaciales, donde la condición del lugar y sus formas de uso están mediatizadas por la capacidad de agencia social de los actores involucrados en la turistificación de dicho espacio geográfico, mediante sendas espacio-temporales.

Estas sendas marcan el proceso de turistificación del espacio geográfico, el cual, según Facundo Martín “es apropiado y ocupado por el turismo, se territorializa de una determinada forma, este se redefine en diferentes escalas (micro, meso, macro), donde los distintos actores y agentes que intervienen en el proceso de desarrollo del turismo lo resignifican según sus racionalidades, intereses, tendencias, vocaciones y espacialidades específicas" (Martín, 2012: 144). De acuerdo con lo anterior, es clave, para caracterizar el proceso de turistificación mediante las sendas espacio-temporales, por una parte, identificar a los actores sociales y el rol que éstos cumplen, tanto en sus intereses y estrategias y por otra, las escalas espaciales y temporales en las cuales se mueven. Las escalas temporales y espaciales están mediatizadas por la condición del capitalismo, en efecto, Henri Lefebvre (1974) propuso que el capitalismo, mediante la industria del ocio se ha apropiado de espacios vacantes, señala: "Con la industria del ocio el capitalismo se ha apropiado de los espacios que quedaban vacantes: el mar, la playa, la alta montaña. Ha creado una industria nueva, una de las más potentes: la industria del ocio" (Lefebvre, 1974: 220). Por su parte, Antonio Nogués, señala que "el turismo es, quizás, la creación más perfecta del Capitalismo por cuanto no sólo consume lugares y territorios, esculpe paisajes sobre la materia que constituyen los sueños: el deseo, o perpetúa relaciones de dependencia sino que, en 
la dimensión expresiva, produce sentidos y significados, y convierte al lugar a través del espacio turístico actualizando los espacios y los ritmos de acuerdo con los principios definidos por el mercado global" (Nogués, 2012:152). Así, el turismo, se ha transformado en un fenómeno relevante de la sociedad capitalista contemporánea, ya sea por la cantidad de viajes, empleos, recursos, infraestructuras; como por la construcción de imaginarios y de experiencias, los cuales se configuran como una mercancía básica de transacción e intercambio, mediante la consolidación de un sector empresarial: hotelería, transporte aéreo, agencias de viajes, operadores turísticos; un grupo de consumidores: viajeros, turistas y veraneantes, los cuales confluyen en el turismo como un sistema de actores, de prácticas y de espacios que participan en la "recreación", por el desplazamiento y el habitar temporalmente fuera del lugar cotidiano (Knafou y Stock, 2003. En: Hiernaux, 2008: 181).

El presente documento se abocará a analizar el proceso de producción de espacios turísticos, a través de la conceptualización de las sendas espacio-temporales, como una propuesta teórico-metodológica para reconocer la turistificación de la Araucanía andinolacustre entre 1900 a 1940.

Para ello, se profundizará en la noción de espacio geográfico y su vinculación con el turismo, luego se analizarán las conceptualizaciones de imaginarios y experiencia turística. Conceptos centrales en la idea de sendas espacio-temporales. Finalmente, se busca aplicar estos enfoques y conceptos a la Araucanía andino-lacustre en el periodo 1900-1940. Se ha optado por este periodo de manera intencionada, con el fin de reconocer en él los primeros pasos de la turistificación del espacio geográfico andino-lacustre, a partir de las expediciones de los primeros viajeros con motivaciones turísticas y el rol del Estado en la construcción de la infraestructura y equipamiento para el desarrollo de la actividad turística.

\section{LA PRODUCCIÓN SOCIAL DEL ESPACIO TURÍSTICO}

Se propone que la producción de espacios turísticos se reconoce en sendas espaciotemporales. Para conceptualizar la idea de sendas, en primer lugar, nos referiremos al concepto de espacio geográfico y su vinculación al turismo. El espacio geográfico es uno de aquellos conceptos más controversiales en la historia del pensamiento geográfico. Sus distintas interpretaciones, plantean un enorme desafío al proceso investigativo en turismo. Sin el ánimo de realizar una genealogía del concepto de espacio geográfico, nos enfocaremos en dos dimensiones. En primer lugar, la perspectiva de espacio material-producido, y en segundo lugar, el espacio vivido-concebido.

En el marco de la dinámica del turismo, esta doble dimensión del espacio geográfico posibilita entender las relaciones naturaleza y la sociedad como parte de un sistema de configuraciones de objetos materiales y sociales (Santos, 1996a), mediados por relaciones sociales de poder, donde se usa el espacio, se desarrolla el trabajo y se divide entre agentes y lugares, a partir de relaciones disímiles de poder y disputa (Silveira, 2009), que paulatinamente van dando forma al territorio como un espacio que comprende diversos grados apropiación, tanto simbólica, como utilitaria, de cooperación como de desposesión. 


\subsection{El espacio geográfico producido y el turismo}

Henri Lefebvre (1974) visualiza al espacio como resultado de la producción social. La concepción práctica del espacio no necesariamente tiene que ver con su abstracción; la abstracción es resultado de la práctica. De esta manera, elabora cuatro hipótesis sobre el espacio: el espacio como la forma pura (absoluto); el espacio social como un producto de la sociedad (material); el espacio como un instrumento político (poder) y el espacio como producción de las relaciones sociales y reproducción de determinadas relaciones (producto).

Para Lefebvre (2013) el espacio social contendrá relaciones de producción y de reproducción; las primeras vinculadas a la división del trabajo y su organización y las segundas a la reproducción de relaciones sociales. Estas relaciones se diferencian y entrecruzan en el espacio social, mediante lo que denomina como las practicas espaciales, las representaciones del espacio y los espacios de representación (Lefebvre, 2013: 92).

Las practicas espaciales se asocian a los mecanismos que aseguran la producción y reproducción; a su vez, las representaciones del espacio se vinculan las formas cómo esas relaciones de producción y reproducción se imbrican en un sistema de códigos y signos; en tanto, los espacios de representación los asocia a los simbolismos e imágenes (Lefebvre, 2013: 92-98).

Otro referente en este enfoque es David Harvey, quien plantea que existen varias maneras de concebir el espacio, señala: "Si consideramos el espacio como algo absoluto, entonces se convierte en «algo en sí» con una existencia independiente de la materia. Entonces, el espacio es poseedor de una estructura que podemos usar para clasificar o individualizar los fenómenos. La tesis del espacio relativo mantiene que éste debe ser entendido como una relación entre objetos que existe sólo porque los objetos existen y se relacionan entre sí. El espacio se puede considerar como relativo también en otro sentido, y he escogido para ello la expresión de espacio relacional, esto es, el espacio considerado, al modo de Leibniz, como algo contenido en los objetos en el sentido de que se dice que un objeto existe en la medida en que contiene en su interior y representa relaciones con otros objetos" (Harvey, 2007a: 5-6).

Tanto Lefebvre como Harvey intentaron superar la tradicional dicotomía entre tiempo y espacio en el enfoque marxista. En efecto, Elden (2004: 93) señala que para Lefebvre "el espacio se ha formado y moldeado por elementos históricos y naturales, a través de un proceso político". En tanto, en el caso de Harvey, su propuesta se basó en el llamado "materialismo histórico-geográfico, donde intenta llenar los vacíos del materialismo histórico de Marx. Argumenta que la tendencia del capitalismo a la crisis por la hiper-acumulación, se absorben o movilizan, sin amenazar el sistema, a través del desplazamiento temporal: mediante la inversión de capital y trabajo en infraestructuras físicas y sociales y la aceleración en los tiempos de rotación del capital y, espacial: mediante la expansión geográfica y la producción de nuevos espacios (Harvey, 1990 y 2004).

De esta forma, la noción de producción de espacios turísticos se vincula al espacio material-producido en relación a la dinámica capitalista. Tal como señala Harvey (2007a), el capital tiende a ejercer un control exclusivo de elementos únicos, no reproducibles y posibles de ser comercializados. Por lo tanto, el espacio geográfico puede ser comercializado a través del turismo, y generar renta a través de propiedad del suelo y el control de la infraestructura necesaria para su puesta en circulación como mercancía (Harvey, 2007a). 
En esta línea, Nogués (2012) propone analizar al turismo como una elaboración del capitalismo, ya que: “... ha logrado comercializar lo intangible y erigirse en uno de los más efectivos mediadores en la producción de sentidos y significados de la actualidad: de deseos. Porque aunque resulte un trazo excesivamente grueso, las condiciones históricas de esta peculiar manera de combinar el ocio (dimensión tiempo) y el viaje (dimensión espacio) vienen determinadas por los desarrollos del capital y por la ideología que los sustenta: el capitalismo" (Nogués, 2012: 158). El capitalismo, al turistificar el espacio, lo hace desde la materialidad (conectividad, infraestructura, equipamiento) y desde la inmaterialidad (la experiencia turística), otorgándole una dimensión de mercancía, al promocionarla y transarla como un bien en el sistema turístico, que vincula espacios en sus distintas escalas. Efectivamente, tal como afirma Santana (2008: 19), el turismo se enmarca en la necesidad de expansión económica y cultural de las sociedades occidentales, por una parte, a través del desplazamiento de sus excedentes, como a la necesidad de ocupación de los tiempos de ocio, mediante el desplazamiento colectivo no forzado.

En esta línea se enmarca la crítica marxista al turismo, como una forma de recuperación que hace el capital de un espacio-tiempo liberado a través del consumo turístico (Hiernaux, 1999). Esto, en palabras de Blazquez y Murray (2010) se traduce en que "el turismo, como las otras actividades económicas, sigue la dinámica propia del sistema capitalista que se basa en la expansión mediante pulsaciones de innovación tecnológica e incorporación de nuevos productos y territorios, estimulada por el afán de lucro personal de los productores que pretenden acumular el máximo de beneficio en detrimento de sus costes -como son los costes laborales y su flexibilización, o los perjuicios sociales y ambientales" (Blazquez y Murray, 2010: 74). En consecuencia, el turismo es un vehículo para la ampliación de las fronteras geográficas del capital. En efecto, en los espacios turísticos, "las autoridades políticas 'locales' priorizan la ejecución de las actividades empresariales 'globales', por ejemplo, modificando la legislación urbanística, financiando la construcción de infraestructuras o tolerando la expansión de amplios sectores de economía informal (González y Mantecón, 2014:688).

De acuerdo con lo anterior, el turismo implica una apropiación material del espacio, que considera al territorio como una mercancía generadora de utilidades, fuente de recursos, área geopolítica, que enfatiza el uso utilitario del territorio (Giménez,1996; 2001).

En este sentido, el espacio geográfico puede ser considerado como una configuración compleja de relaciones de producción y de reproducción, que dibujan formas espaciales que adquieren significado -en y por- las relaciones sociales que se inscriben en la espaciotemporalidad de las prácticas materiales y simbólicas de los sujetos. Es decir, puede ser "continente" donde se localizan los atractivos turísticos, las infraestructuras, el anclaje del capital, pero también un espacio con significado y fuente de la experiencia turística, el espacio contenido (Martínez, 2014).

\subsection{El espacio geográfico vivido-concebido}

La segunda perspectiva relevante acerca del espacio es la vivida-concebida. Al respecto, Hiernaux y Lindón (1993) plantean, que el espacio debe ser estudiado a través de los sentidos y significados que las personas le otorgan, avanzando de las concepciones 
iniciales de "espacio percibido" a espacio concebido o vivido. Dicho tránsito ha sido guiado por la profundización de la corriente constructivista, "al subrayar que los sentidos y significados de espacio son construidos a través de un proceso de contraste entre elementos materiales y las representaciones, esquemas mentales, ideas e imágenes con los que individuos se vinculan con el mundo, que por otra parte son de carácter socio-cultural" (Lindón, et al. 2006: 12).

Es decir, se transita desde la materialidad a la inmaterialidad del espacio, en efecto, Lindón postula, "Los sujetos no sólo construyen los lugares cuando levantan viviendas, edificios, talan bosques, abren caminos, cultivan tierras. También se construyen lugares al hablar de ellos, y hacerlo de cierta forma, enfatizando algo, omitiendo otro rasgo, asociando ciertos fenómenos con otros (...) Los lugares también son construidos por los sentidos y significados que se le atribuyen" (Lindón, 2010:33). Este planteamiento es desarrollado a partir del "constructivismo geográfico", que se funda desde: a) espacio visto desde el sujeto; b) lugar en la dialéctica espacio y sociedad; c) lugar en la dialéctica entre formas espaciales y sentidos del lugar, y d) lugares a partir de la experiencia (Lindón, 2007).

La apropiación del espacio o como diría Edward Soja, "la producción social de la espacialidad humana, se ha convertido en algo tan fundamental para entender nuestras propias vidas y nuestros contextos vitales" (Soja, 2010: 184). El espacio adquiere una triple dimensión, espacio percibido, es decir a sus prácticas y materialidad; espacio concebido, las representaciones de dicha materialidad (imaginarios) y espacio vivido, al conjunto de acciones de ejercicio de poder en el espacio (Soja, 2010). Las ideas planteadas por Soja tienen su punto de partida en los postulados de Henri Lefebvre en su obra "La Producción del espacio". En ésta, Lefebvre (2013), plantea una teoría global para comprender el espacio social, indica la necesidad de reconocer a la sociedad actual a través del espacio producido. Argumenta que se debe observar al espacio como una totalidad, saltando de las "cosas" en el espacio, a la producción de éste. Para ello, propone observar el espacio como un producto social, resultado de acciones, practicas, relaciones, experiencias, las cuales sintetiza en la triada del espacio: esto es, espacio percibido (prácticas espaciales), espacio concebido (representación espacial) y espacio vivido (espacios de representación).

Por su parte, Doreen Massey enfatiza que el espacio esta imbuido de tiempo, señalando: “...el espacio es una dimensión que atraviesa relatos/trayectorias, pero no para estabilizarlos en una superficie en la que las vidas de los demás están quietas, y en la que los trastornos inherentes a la multiplicidad están suturados en la coherencia. El espacio está, en este sentido, intrínsecamente imbuido con el tiempo. El espacio es una simultaneidad de trayectorias inacabadas y en curso" (Massey, 2012a: 205). Así, estas sendas manifiestan un conjunto de relaciones en permanente desarrollo e inacabas y recurriendo nuevamente a Massey, "son abiertas, porosas, inventadas y particularizadas como producto de la interacción. Puede tratarse de una «comunidad local» (un grupo indígena, digamos), o un Estado-nación, donde la hibridación interna esta, no obstante, relacionada con un espacio particular". (Massey, 2012b: 152).

Doreen Massey (2012b), propone observar esas interrelaciones a partir de tres afirmaciones, la primera, que esas interrelaciones se encuentran inmensas desde lo global a lo más ínfimo de la intimidad; la segunda, que son múltiples y coexisten en distintas trayectorias; y la tercera, que las relaciones "están necesariamente implícitas en las practicas 
materiales que deben realizarse, siempre está en proceso de formación, en devenir, nunca acabado, nunca cerrado" (Massey, 2012b: 158).

A partir de los autores indicados precedentemente, se puede sostener que, en la noción del espacio vivido, las dimensiones de la materialidad y la inmaterialidad no se encuentran separadas entre sí, por el contrario, se interrelacionan y son esas interrelaciones las que le otorgan sentido y configuran el espacio, interacciones que se desarrollan a diversas escalas.

En efecto, las escalas, ya sean de tiempo o de espacio, en el espacio vivido vinculan materialidad e inmaterialidad en una dinámica de movimiento, que Lindón (2007) caracteriza como tensiones constantes entre las permanencias y los cambios, entre estancias cortas o extensas de duración en el tiempo y en el espacio.

De acuerdo con Lindón (2007), la noción de espacio vivido tiene sus orígenes en las geografías francófonas. Según esta autora, los principales referentes se encuentran en Armand Frémont (1976) y Cuy Di Meo (1991), quienes sentaron las bases conceptuales para la noción del espacio vivido, destacando a lo menos tres aportaciones: a) que el espacio vivido está asociado a las experiencias y representaciones del espacio por parte de los sujetos; b) el espacio vivido está vinculado a los intercambios sociales que construyen nuestra representación del mundo y le asignan significados y sentidos subjetivos, y c) el espacio vivido integra todas distancias y todas las complejidades de la vida social (Pianissi, 2015).

De esta manera, las prácticas turísticas, se sustentan en un modelo espacio-temporal radicalmente opuesto al que prevalece en el mundo del trabajo, donde la cotidianeidad se construye en un mundo distinto -el ocio-, y las reglas sociales, prácticas e identidad se construyen en un ambiente relativamente efímero.

En efecto, para Hiernaux (1999) el turismo representa una "implicación paradójica", dado que expresa lateralidades de la vida social que tienen lugar en espacio-tiempos diferentes a los habituales (Hiernaux, 1999: 104). De esta manera, es posible distinguir nuevas formas de apropiación del espacio cotidiano. Señala: "la turistificación de la vida cotidiana se produce por tanto a partir de la creciente filtración de gotas de ocio en el manto tan impermeable de la vida orientada hacia el trabajo" (Hiernaux, 1999: 115).

En esta línea, Pinassi y Ercolani (2017), sostienen que el concepto “entre-lugares turísticos" permite articular la vivencia/experiencia de los turistas en un espacio turístico dado. Para ello, el "entre lugar" es definido como "el espacio donde, la relación con el otro, el lugar del otro es asimilado y negociado al mío, sin que haya la efectivización del arraigo y de la objetivación de ese lugar, quedando restringido a las representaciones e imaginarios colectivos" (Da Soller y Castrogiovanni, 2014, citado por Pinassi y Ercolani, 2017: 54).

El espacio geográfico adquiere una doble dimensión: producido y concebido. Como espacio producido se vincula a las prácticas, a la materialidad y como espacio concebido, a las representaciones de dicha materialidad, los imaginarios, como también al conjunto de acciones de ejercicio de poder en el espacio (Soja, 2010). Pero estas dimensiones no se encuentran separadas entre sí, se interrelacionan y son esas interrelaciones las que le otorgan sentido y configuran el espacio, interacciones que se desarrollan a diversas escalas.

A partir de lo anterior, los espacios turísticos son un producción material de atractivos, equipamientos e infraestructuras, construidas por diversos agentes (Estado, empresarios, comunidad local, otros), los cuales se relacionan en diferentes escalas con las expectativas previas y la experiencia vivida por los turistas una vez desarrollada la visita, lo que 
implica que es a la vez una producción vivencial. De esta forma, el espacio turístico se representante en una construcción concebida e imaginaria del mismo, la cual se comunica y reproduce a través de diversos dispositivos de comunicación y promoción.

\subsection{Imaginarios y la experiencia turística}

La noción de imaginario es definida por Hiernaux como "el conjunto de creencias, imágenes y valoraciones que se definen en torno a una actividad, un espacio, un periodo o una persona (o sociedad) en un momento dado. La representación que el imaginario elaborada de un proceso es construida a partir de imágenes reales o poéticas" (Hiernaux, 2002: 8). Los imaginarios, por lo tanto, permiten reconocer que el espacio geográfico no se reduce a lo material, pero tampoco que lo inmaterial se reduce a la escala individual. Los imaginarios se modelan de manera individual y colectiva, en esta línea se observa el planteamiento de Berdoulay (2012) quien señala que el "imaginario constituye un material a partir del cual se elaboran los relatos que sirven para sustentar recíprocamente a los sujetos y los lugares. En otros términos, la co-construcción del sujeto y del lugar pasa por la mediación de imaginarios geográficos" (Berdoulay, 2012: 50).

En este sentido, el imaginario turístico es definido como "aquella porción del imaginario social referido al hecho turístico, es decir, a las numerosas manifestaciones del proceso societario de viajar" (Hiernaux, 2002:8).

Hiernaux (2015) propone cinco clasificaciones de imaginarios turísticos en las sociedades capitalistas actuales (Figura 3), las cuales, según el autor, se superponen o también pueden derivar una de otras o contradecirse se presentan las cinco clasificaciones.

\section{Figura 1}

\section{CLASIFICACIONES DE IMAGINARIOS TURÍSTICOS}

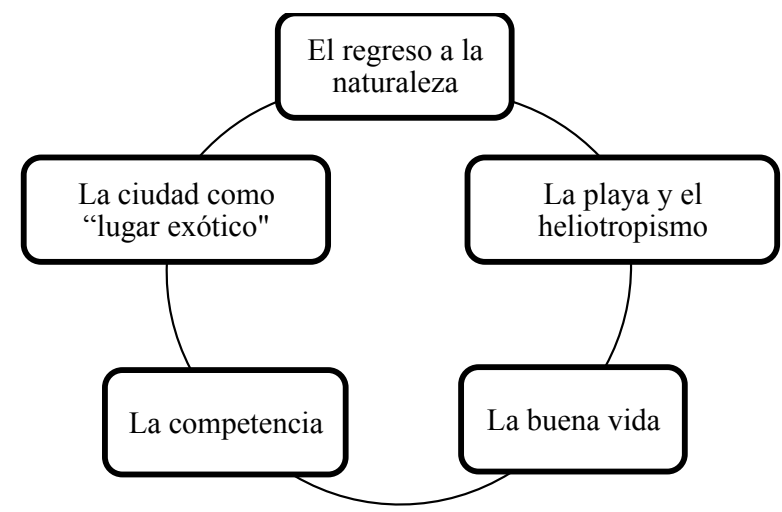

Fuente: Hiernaux, 2015.

Los imaginarios turísticos propuestos por Hiernaux (2015) tiene como elementos comunes, la noción de "extrañeza" como el mismo lo señala, en relación a los ambientes 
cotidianos de la vida social, pero también la noción de "fantasía" que se fija en éstos. En esta línea, el turista es capaza también de introducir dimensiones subjetivas a la experiencia turística; este autor afirma que "introducir las dimensiones subjetivas en el estudio del turismo y en particular de la experiencia turística, nos aleja de las antinomias tan frecuente en el mismo que observan la experiencia turística desde perspectivas en blanco o negro que fueron particularmente apreciadas a finales de los setenta y en los ochenta, sea para ensalzar el turismo sea para criticarlo (Hiernaux, 2015:72).

De esta manera, la práctica del turismo se consuma mediante la experiencia o vivencia que el turista realiza en un espacio turístico determinado, que es la cristalización espacio-temporal de la movilidad, el deseo de experienciar lugares diferentes a los habituales, basados en una expectativa, una preconcepción imaginaria del lugar a visitar, pero también, las formas como se transmiten y recrean dichos imaginarios por el turista. Así, los imaginarios, "trasladan las posibles ensoñaciones y fantasías individuales a un plano colectivo, como construcciones socialmente compartidas, aunque provengan, en buena medida, de la elaboración individual de un imaginario" (Hiernaux, 2015:75).

Ahora bien, existen diversos enfoques para aproximarse a la experiencia turística. Por una parte, como una vivencia de carácter sensorial, vinculado a las expectativas previas de los turistas respecto del destino a visitar, y por otra, a su condición de mercancía, como producto de consumo basado en los dispositivos de promoción utilitaria de los patrimonios culturales, identitario y naturales de los espacios turísticos y los destinos presentes en él.

En efecto, para el primer caso, Fuentes et al., (2015) propone siete dimensiones de la experiencia turística (Tabla 1), postulando que ellas tienen su origen en las características sociales y culturales de las personas y que de acuerdo con dichos orígenes se mediatiza la experiencia, presentándose en tapas: una anterior al viaje; otra, en el desarrollo del mismo y una final, posterior a éste. De esta manera, "Las experiencias son existenciales y están encarnadas en las personas, ya que son personales y únicas (...) los factores sociológicos, psicológicos y contextuales, determinan el resultado de la experiencia, existiendo así condicionantes de la experiencia turística que pueden ser clasificados como: tiempo, dinero, conocimientos, habilidades y actitudes que dependen de los individuos" (Fuentes et. al., 2015: 75).

Tabla 1

\section{DIMENSIONES DE LA EXPERIENCIA TURÍSTICA}

\begin{tabular}{|l|l|}
\hline Dimensiones & Descriptor \\
\hline Involucración del turista & $\begin{array}{l}\text { Integrando los elementos del entorno externos al turista con los } \\
\text { internos del individuo, siendo la naturaleza un facilitador clave }\end{array}$ \\
\hline Shock sensorial & $\begin{array}{l}\text { Apelando a los cinco sentidos y generando una excitación y } \\
\text { estimulando al turista, creando sorpresa y un entorno de escape }\end{array}$ \\
\hline Autenticidad & Generando placer y un entorno agradable y de entretenimiento \\
\hline Diversión & Generando placer y un entorno agradable y de entretenimiento \\
\hline Sociabilidad & $\begin{array}{l}\text { Proporcionando la posibilidad de compartir y de participar en una } \\
\text { comunidad }\end{array}$ \\
\hline
\end{tabular}




\begin{tabular}{|l|l|}
\hline Dimensiones & Descriptor \\
\hline Personalización & $\begin{array}{l}\text { Que aporta libertad y control, donde el turista siente que puede } \\
\text { elegir y definir en cierta medida gracias a su habilidad y esfuerzo el } \\
\text { resultado final, consiguiéndolo por el mismo }\end{array}$ \\
\hline $\begin{array}{l}\text { Autodescubrimiento y } \\
\text { trasformación }\end{array}$ & $\begin{array}{l}\text { Donde a través de un aprendizaje y un intercambio de valores y } \\
\text { reflexiones, el turista siente un cierto cambio }\end{array}$ \\
\hline
\end{tabular}

Fuente: Fuentes, et al. (2015).

La perspectiva de la experiencia como mercancía se vincula a la noción de la capacidad del capital por producir símbolos con significación cultural, sustrayendo las relaciones sociales de las dinámicas interaccionales en el espacio, a las cuales hace mención Doreen Massey (2012a). En efecto, tal como plantea Zukin, citado por López y Marín (2010) existe una producción paralela del espacio, asociada a la lógica de la movilidad del capital. Caracteriza a dicha producción paralela como "la producción del espacio con su sinergia de inversión de capitales y significados culturales, y la producción de símbolos que construye un intercambio comercial, así como un lenguaje de identidad social" (Zukin, 2001: 26. En: López y Marín, 2010: 225). En consecuencia, la experiencia turística como mercancía estaría asociada a la mercantilización del espacio, donde la identidad y valores culturales son convertidos en productos transables. Así lo indican López y Marín (2010) “...comprendemos la mercantilización del espacio como el proceso mediante el cual se sustraen las relaciones sociales del lugar en términos de experiencia histórica y social (de pertenencia, identidad, cotidianidad, vida material, o sentido sagrado, por ejemplo), para que un lugar y algunos de sus contenidos, pasen a convertirse primordialmente en producto para ser incorporado como mercancía al circuito del mercado cultural" (López y Marín, 2010: 229). En este sentido, la experiencia turística como mercancía encarna valor de uso vinculada en relación a la satisfacción de necesidades humanas, en este caso el ocio; y valor de cambio, como formas de producción de dichos valores de uso (división del trabajo, especialización, materias primas, etc.) (Harvey, 1990: 17).

La experiencia turística, junto con adquirir esa doble condición, al ser una vivencia y una mercancía, tiene su manifestación espacio-temporal, porque se desarrolla en contextos diferentes al espacio-tiempo del trabajo, del hogar, de la familia y personal y requiere de un desplazamiento a espacios distintos de los entornos habituales, éstos son los espacios turísticos (Volo, 2009). En consecuencia, la construcción de un imaginario turístico, junto con estar presente las expectativas, intereses y experiencias de los turistas, también se configuran a partir de los discursos que sobre ellos se despliegan por agentes con diversa capacidad de agencia (Martínez, 2014).

\section{SENDAS ESPACIO-TEMPORALES DE PRODUCCIÓN DE ESPACIOS TURÍS- TICOS}

Tal como afirmamos anteriormente, el espacio geográfico adquiere una doble dimensión: producido y concebido. Como espacio producido se vincula a las prácticas, a la materialidad y como espacio concebido, a las representaciones de dicha materialidad, los 
imaginarios, como también al conjunto de acciones de ejercicio de poder en el espacio (Soja, 2010). Pero estas dimensiones no se encuentran separadas entre sí, se interrelacionan y son ellas las que le otorgan sentido y configuran el espacio, interacciones que se desarrollan a diversas escalas.

A partir de lo anterior, los espacios turísticos son una producción material de atractivos, equipamientos e infraestructuras, construidas por diversos agentes (Estado, empresarios, comunidad local, otros), los cuales se relacionan en diferentes escalas con las expectativas previas y la experiencia vivida por los turistas una vez desarrollada la visita, lo que implica que es a la vez una producción vivencial. De esta forma, el espacio turístico se representa en una construcción concebida e imaginaria del mismo, el cual se transmite y reproduce a través de diversos dispositivos de comunicación y promoción.

La propuesta de sendas espacio-temporales de producción de espacios turísticos tiene su fuente en tres enfoques geográficos, el regional de Hägerstrand, el crítico de Lefebvre, Harvey y Santos, y el vivencial de Hiernaux. Aunque es arriesgado plantear una yuxtaposición de tres corrientes distintas de pensamiento, se busca presentar una propuesta de análisis que se aproxime al entendimiento de los espacios turísticos.

De acuerdo con Hägerstrand la idea de sendas permite articular el tiempo y el espacio, al respecto señala: "el tiempo tiene una importancia vital cuando se trata de situar juntas a personas y cosas para el funcionamiento de los sistemas socioeconómicos, ya experimenten cambios a largo plazo o descansen en algo que podría definirse como un estado estable (...) el tiempo se mezcla con el espacio en una entidad espaciotemporal indivisible" (Hägerstrand, 1970: 96. Citado por Silveira, 2010: 19).

La propuesta de Hägerstrand se basa en entender mejor qué significa cuando una ubicación tiene, no solo coordenadas espaciales, sino de tiempo. De esta manera la ubicación en el espacio no puede ser separada del transcurso del tiempo. Propone que en el tiempo-espacio, el individuo describe una trayectoria, empezando al punto del nacimiento y terminando al punto de la muerte, así trayectorias de vida (diaria, semanal) se grafican descomponiendo el espacio tridimensional en una planicie bidimensional, o aun en isla unidimensional. Su propuesta se basa en "Un modelo de tejido tiempo-espacio en el sentido de un flujo de trayectorias de vida, controlado por capacidades dadas y el movimiento a través de un sistema de restricciones exteriores que juntas dan paso a ciertas distribuciones de probabilidad de situaciones para los individuos, debería, en principio, ser aplicable a todos los aspectos de la biología, desde las plantas hasta los animales hasta los seres humanos" (Hägerstrand, 1970: 20).

Hägerstrand desde la ciencia regional busca reconocer el destino del ser humano en un ambiente de creciente complejidad, señalando que la ciencia regional trata de las personas, no de las localizaciones (Hägerstrand, 1970). Desde allí, plantea la relación tiempo-espacio en las trayectorias de las personas, criticando de esta manera los probabilísticos de comportamiento humano. Estas trayectorias de vida (diaria, semanal) se grafican descomponiendo el espacio tridemensional en una planicie bidimensional, o aun en isla unidimensional" (Hägerstrand, 1970: 8). Este modelo o trayectorias de tiempoespacio son controladas por "capacidades dadas y el movimiento a través de un sistema de restricciones exteriores que juntas dan paso a ciertas distribuciones de probabilidad de situaciones para los individuos" (Hägerstrand, 1970: 20). 
Las restricciones a las que se refiere Hägerstrand (1970) son:

De capacidad: limitado al individuo por su capacidad biológica (dormir, comer, etc.)

De enlace: casa-trabajo, transporte (dónde, cómo, cuándo y cuánto tiempo el individuo puede juntarse con otros individuos)

De autoridad: cosas o eventos bajo un tipo de control (Estado o costumbre)

A partir de las ideas de Hägerstrand y de la geografía del tiempo, la preocupación por los desplazamientos, la movilidad espacial y flujos se asocian al espacio móvil y tiempo cronometrado, han tenido una significativa resonancia en estudios vinculados a fenómenos urbanos. El trabajo de Jirón y Mansilla (2013), es un ejemplo de ello, ya que plantean que "la movilidad cotidiana urbana puede ser entendida como "aquella práctica social de desplazamiento diario a través del tiempo-espacio urbano que permite el acceso a actividades, personas y lugares (...) para entender las consecuencias sociales, económicas, culturales y espaciales que genera sobre la conformación del espacio urbano y los distintos tipos de experiencia de sus habitantes" (Jirón y Mansilla, 2013: 58).

A su vez, las preocupaciones por las prácticas ancladas al lugar, se vinculan a las nociones de arraigo, la subjetividad y los diferentes sentidos y significados otorgados al espacio. Esto es reconocible en el trabajo de Rodríguez (2015) que se enmarca en esta categoría, ya busca explorar, en el contexto del Cementerio general de Santiago, la relación simbólica entre el cuidador y el patio que tiene a su cargo, "desde la experiencia y relación del cuidador como figura productora de un espacio dotado de herencia y de tradiciones (y) develar aquellos elementos socioculturales que se han desarrollado a lo largo del tiempo, y que dotan de sentido a una espacialidad definida como el patio que tiene a cargo cada uno de los cuidadores de este cementerio" (Rodríguez, 2015: 118).

Por su parte, los estudios centrados en patrones y rutinas de práctica se basan en los desplazamientos y escenarios en movimientos que se reiteran en el tiempo, por lo tanto, se vinculan a las ideas de Hägerstrand de rutinización o ciclos en los cuales una práctica se repite en el tiempo-espacio. En efecto, tal como lo plantean Jirón y Mansilla (2013), "un análisis detenido de las prácticas de movilidad cotidiana revela que si bien el transporte puede ser un gran obstáculo para la accesibilidad, es necesario generar una aproximación a otros tipos de barreras, como las que se presentan más adelante, que den cuenta de la multiplicidad de obstáculos que las personas enfrentan cotidianamente, comprendiendo los ritmos, rutinas y hábitos propios de la vida diaria que dan una "espesura" a la accesibilidad" (Jirón y Mansilla, 2013: 54).

De esta manera, las ideas de Hägerstrand se centraron en la cotidianeidad desde el comportamiento y movilidades individuales de los sujetos, las que se han aplicado al estudio del turismo principalmente en ámbito de la movilidad de los turistas y el transporte. Respecto de la movilidad de los turistas, a partir de las propuestas de Hägerstrand, contribuyeron a una comprender que estas categorías de tiempo y espacio son inseparables en el contexto del viaje, por ello la investigación turística se ha centrado, a partir de estos planteamientos, en el seguimiento de las rutinas de los turistas en sus viajes, hacia y desde el destino turístico, por lo tanto, sitúa al turismo dentro del contexto de toda la movilidad humana (Hall, 2005. Grinberger et al., 2014).

Por lo tanto, estas propuestas se mantienen el ámbito de la cotidianeidad del fenómeno turístico, sin embargo, al posicionarse en el ámbito exclusivo de la vida cotidiana, no 
reconoce la condición de historicidad del espacio, ya que supone una trayectoria espaciotemporal de los individuos, no así del espacio mismo. Esto es relevante, toda vez que las prácticas sociales se vinculan a las formas de apropiación del espacio, en su vertiente utilitaria y simbólica por agentes que despliegan diversas estrategias y discursos de turistificación del espacio. De esta manera, estas estrategias de apropiación por parte de los agentes turísticos se vinculan a la construcción de un imaginario turístico respecto del territorio, asociado a la promoción de experiencias turísticas por parte de los visitantes.

Es por ello, que planteamos una transposición del concepto de "sendas" de Hägerstrand al espacio turístico. Esto es, que las sendas espacio-temporales aluden al tiempo en su condición de circulación, rotación y consumo en el "hecho turístico", partiendo por una noción de tiempo vinculada a la construcción de paisajes turísticos altamente valorados y sensibles, es decir, dimensionar el tiempo que ha llevado la configuración de un espacio turístico y las rutinas de tiempo en los turistas. En cada uno de ellos, la condición de tiempo es distinta. Por una parte, el tiempo medido como consumidor de espacio (fricción de la distancia), el tiempo como rutinas de movimientos (prácticas materiales) y el tiempo como memoria (patrimonio).

Esto obliga a mirar las sendas desde una perspectiva multiescalar, entiendo la escala como una construcción social, al respecto, Swyngedouw señala: "las escalas espaciales nunca se mantienen fijas, sino que son redefinidas, impugnadas y reestructuradas en lo referente a su extensión, contenido, importancia relativa e interrelaciones" (Swyngedouw, 1997: 141. Citado por Harvey, 2007b: 97). En esa línea Harvey sostiene que las escalas dependen de las innovaciones técnicas, las condiciones políticas cambiantes, la lucha de clases y otras formas de luchas sociales (Harvey 2007b: 96). Por su parte, Leitner (2008) destaca tres aspectos asociado a la escala desde la perspectiva constructivista, el primero, que la escala se construye socialmente, por lo tanto, no es fija ni pre-determinada. En segundo lugar, lo social y lo espacial son aspectos mutuamente constitutivos; y en tercer lugar, que la construcción de escala incorpora la noción de poder, a través de prácticas materiales (producción, distribución, consumo, regulación, vigilancia, gestión) o las prácticas discursivas (discursos sobre la globalización o el Estado-nación) de individuos, grupos e instituciones (Leitner, 2008: 238).

En consecuencia, siguiendo las ideas de Hägerstrand, los conceptos de espacio geográfico aquí tratados, la noción de agentes, estructura, estrategias, tácticas y dispositivos, se postula que las sendas espacio-temporales se desenvuelven en las categorías de tiempo y espacio geográfico a través de trazos o componentes que la constituyen y que se definen a continuación:

a) Los agentes, entendidos como el conjunto de actores sociales y económicos que se desenvuelven en la actividad turística.

b) Organización, hace referencia al comportamiento y estructuración del sistema turístico, en su dimensión económica, política y social. Tiene una dimensión multiescalar, una jerarquía y opera en torno a redes, las cuales pueden ser competitivas o de colaboración; de dominación o de resistencia; estatales o privadas; locales o globales. No necesariamente actúan dicotómicamente, sino más bien como complejo entramado de redes y flujos organizacionales. 
c) Experiencia turística, definida como una vivencia de carácter sensorial, vinculada a las expectativas previas de los turistas respecto del destino a visitar, y a su condición de mercancía, como producto de consumo basado en los dispositivos de promoción utilitaria de los patrimonios culturales, identitarios y naturales de los espacios turísticos y los destinos presentes en él.

e) Imaginarios, como creencias, imágenes, valoraciones y representaciones que se definen en torno al espacio turístico, ya sea de manera individual o colectiva. Estos componentes se entrelazan mediante los denominados eventos.

Estos componentes se despliegan de manera espacio-temporal, y se vinculan en las sendas, a través de fracciones de dicho espacio-tiempo que denominaremos eventos. Éstos son claves para comprender la dinámica relacional y creadora de espacio que el turismo tiene y que se dibujan en trayectorias y dejan huellas territoriales (Figura 2).

\section{Figura 2}

\section{MATRIZ GRÁFICA DE LAS SENDAS ESPACIO-TEMPORALES DE PRODUC- CIÓN DE ESPACIOS TURÍSTICOS}

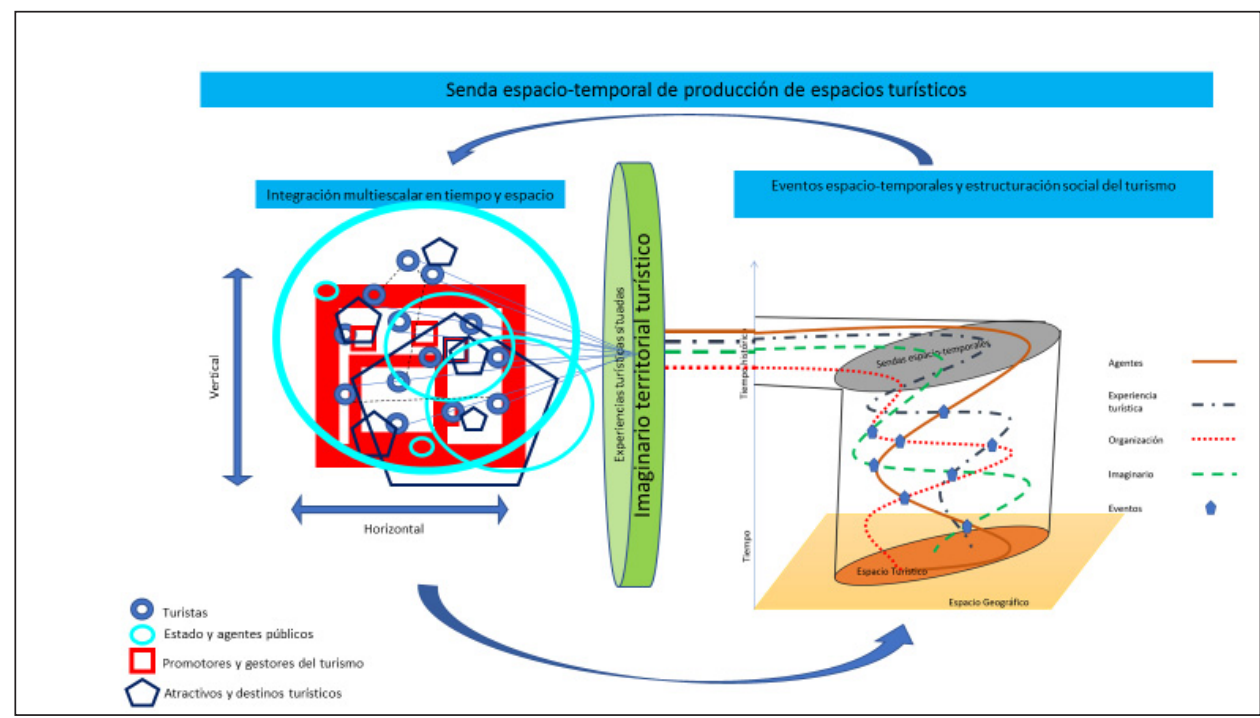

Fuente: Elaboración propia.

La senda de producción de espacios turísticos sostiene que la experiencia turística, vinculada al imaginario territorial turístico es el punto de entrada para entenderla. En efecto, la experiencia turística es la productora y reproductora de dicha senda, en tanto es el resultado de la integración multiescalar del tiempo y el espacio, que a través de prácticas o acciones rutinizadas de los actores sociales, se despliegan estrategias, acciones y tácticas evidenciadas en eventos.

En este sentido, la interacción entre turistas, empresarios o promotores del turismo, junto al Estado y los agentes públicos, se materializan acciones tendientes a generar el "hecho 
turístico", en puntos localizables del espacio, como los atractivos turísticos, pero estos puntos no son meras coordenadas geodésicas, sino que son escenarios de prácticas que permiten el despliegue del imaginario, como asimismo la estructuración social del espacio turístico.

Las sendas, más que representar un proceso lineal de la producción del espacio turístico, es a la vez, una propuesta de análisis del proceso en condición sincrónica y diacrónica, donde los eventos pasan a transformarse en los elementos que configuran la acción de los actores sociales en tanto agentes y donde el turismo es la fuerza que los produce.

María Laura Silveira propone una dialéctica concreta del espacio-tiempo a través de los eventos y las formas. Entiende al evento como unidades de tiempo regidos por su significación social, con capacidad de cambiar la historia y que se puede entender a los eventos como matrices de espacio-tiempo que cambian las cosas, transforman los objetos, dan nuevas características (Silveira, 2013: 21).

En consecuencia, de acuerdo con este planteamiento, no hay eventos sin actores, éste es resultado de la acción. A su vez, sin formas materiales e inmateriales tampoco hay eventos, es una condición de la existencia. Las formas tienen un papel constitucional en la producción de la existencia. Sobre las formas se realizan los eventos. Las formas aseguran continuidad de tiempo a través de sucesivos eventos. Las formas y los eventos son constitutivos de un proceso: sobre un espacio anterior se realizan eventos presentes (Silveira, 2013: 22). De esta manera, se reafirma la condición inseparable de espacio y tiempo. En esa línea Muñoz señala que "es el paso del tiempo y sus hechos lo que permite la interacción entre los individuos y el territorio y también entre ellos mismos (Muñoz, 2006: 237). Para Muñoz, los eventos serían momentos como reflejos simbólicos del tiempo (Muñoz, 2006: 238). En tanto Zusman et al. (2006) agregan que en la dialéctica de espacio-tiempo se reflejan los procesos y prácticas sociales como un producto de histórico. Visto así, cada periodo histórico contiene un conjunto de posibilidades técnicas cuya realización se revela en el espacio geográfico, en un conjunto de formas y eventos, como marcas significativas, eventos dentro de una continuidad que resultan más relevantes para señalar rupturas en las formas contenidas (Silveira, 2013: 22).

En este sentido, de acuerdo con Santos, "Si consideramos el mundo como un conjunto de posibilidades, evento es el vehículo de una o alguna de esas posibilidades existentes en el mundo. Pero el evento también puede ser el vector de las posibilidades existentes en una formación social, es decir, en un país, en una región, o en un lugar" (Santos, 2000: 122). Por lo tanto, los eventos, son fenómenos singulares, ya que son fracciones de espacio-tiempo que cambian las cosas y transforman los objetos, se diferencian en eventos naturales e históricos, cuya duración corresponderá a la naturaleza del mismo y se desarrollan en interrelaciones con otros eventos (Santos, 2000).

\section{METODOLOGÍA}

El punto de entrada metodológico para esta investigación se configura a partir de la noción paradigmática del espacio geográfico como producto social, pero también como espacio concebido. En este sentido, la aproximación metodológica se relaciona con los enfoques crítico y hermenéutico de investigación. Se postula que ambas perspectivas son posibles de conciliar, 
toda vez que el proceso de investigación es asumido como un proceso interpretativo. En este sentido, la propuesta metodológica de investigación se alimenta de las perspectivas críticahermenéutica, entendiéndolas como la posibilidad de "indagar en el significado profundo que puede subyacer a lo manifiesto o a la superficie" (Villarroel, 2006: 115). Por lo mismo, se asume una posicionalidad subjetiva, toda vez que la comprensión del fenómeno de investigación está cruzada no por la explicación casuística, sino que interpretativa.

En este sentido, el enfoque metodológico critico-hermenéutico, observa el espacio turístico como un producto de relaciones de producción y reproducción y siguiendo a Lefebvre: "desde dentro -no sólo desde afuera (descriptivamente)- y globalmente, es decir, yendo sin cesar desde el pasado al presente y viceversa. (...) De tal suerte que la producción y el producto se presentan como dos aspectos inseparables y no como dos representaciones disociables" (Lefebvre, 2013: 96). Por lo tanto, las sendas espaciotemporales, tal como aquí la entendemos, operan como una vía argumentativa de interpretación del espacio geográfico en su transición a un espacio turístico, para lo cual los eventos, como facciones de espacio y tiempo, son igualmente anclajes para sostener la comprensión del proceso turístico, tanto desde la materialidad del fenómeno, como de su inmaterialidad.

Al respecto, Braudel (1968) propone dividir los eventos en larga, media y corta duración, siendo los eventos de larga duración, para él los más relevantes, ya que dan cuenta de procesos de transformación de las sociedades. Esta forma de definir el evento, en relación al tiempo de duración, se vincula también con su extensión en relación al espacio. En efecto, la extensión espacial del evento dependerá de su característica, pero que no se pude localizar en términos absolutos, sino en función de su situación e incidencia (Santos, 2000).

Por otro lado, Worboys (2005), clasifica a los eventos según propiedades: a) Eventos como ocupaciones espacio-temporales de regiones; b) Eventos identificados de acuerdo con sus causas y efectos; c) Eventos como ejemplo de una propiedad o relación en algún momento (Worboys, 2005: 8). Estas tres clasificaciones enfatizan en las propiedades o características de los eventos, más que en su duración.

Por último, una tercera distinción acerca de los eventos es la propuesta por Pianesi y Varzi (2000) quienes reconocer cuatro tipos de eventos, a saber: a) Eventos universales: ocurren en distintos lugares y tiempo; b) Eventos particulares: cosas que ocurren en un lugar y tiempo específico, tiene relaciones finas de causa y efecto con otros eventos. c) Eventos gruesos: impiden que otros eventos se realicen en un mismo lugar y tiempo; d) Eventos finos: distintos eventos pueden ocurrir en un mismo lugar y tiempo.

Tabla 1

CARACTERÍSTICAS CONSTITUTIVAS DE UN EVENTO

\begin{tabular}{|l|l|}
\hline Variable & Descripción \\
\hline Tipo & Finos o gruesos \\
\hline Duración & Larga, mediana, corta \\
\hline Alcance espacial & Macro, meso, micro \\
\hline
\end{tabular}




\begin{tabular}{|l|l|}
\hline Variable & Descripción \\
\hline $\begin{array}{l}\text { Fuerza } \\
\text { impulsora }\end{array}$ & $\begin{array}{l}\text { Fuerzas capaces de producir evento: Estado; una ley; autoridades intermedias; } \\
\text { Empresas, otros. }\end{array}$ \\
\hline Propiedades & Conjunto de dispositivos, discursos y estrategias empleadas \\
\hline Conexiones & Conexión a otros eventos, tanto de manera diacrónica como sincrónica. \\
\hline
\end{tabular}

Fuente: Elaboración propia, en base a Santos (2000), Braudel (1968), Worboys (2005) y Pianesi y Varzi (2000).

Estos eventos, como fracciones de espacio-tiempo, se interrelacionan con los componentes de las sendas. Es dicha interrelación es la que posibilita la producción de espacio turístico. Visto de esta manera, los eventos se traducirían, por ejemplo, en los mecanismos de toma de decisiones de los agentes en la turistificación del espacio geográfico, ya sean éstos el Estado o agentes capitalistas. También constituye un tipo de eventos el viaje, sus motivaciones y formas de materialización, como asimismo las formas de promoción del espacio turístico, sus discursos, mecanismos y lenguaje. Es decir, cuando los agentes se vinculan en la organización del sistema turístico, lo hacen, por ejemplo, mediante dispositivos discursivos de promoción del territorio, allí se produce un evento singular: la promoción del paisaje. A su vez, cuando el Estado chileno, en el marco de su proceso de expansión territorial durante el siglo XIX, impulsó la exploración de los territorios al sur del río Biobío, el viaje se transformó en un evento también de características singulares, que contribuyó a la conformación de un imaginario, por la influencia de las vivencias previas de los viajeros y su acercamiento a espacio explorado.

El área de estudio es la actual Región de La Araucanía chilena, la cual se localiza a 600 kilómetros al sur de Santiago, la capital de Chile. Esta área se caracteriza por un entorno paisajístico homogéneo, con cuencas lacustres (Caburgua, Colico, Villarrica, Calafuén); edificios volcánicos (Villarrica, Llaima, Lonquimay); Parques nacionales, Reservas de la Biósfera Araucarias) y población colona (europeos y chilenos) y aborigen, que han posicionado en esta área a diferentes destinos turísticos (consolidados y en vías de consolidación). Sus antecedentes se remontan a la ocupación militar de los espacios de la "Frontera" a fines del siglo XIX. En efecto, tal como lo plantea el historiador Jaime Flores, “...el esfuerzo del Estado chileno, a partir de 1850, estuvo centrado en ocupar, controlar y desarticular el antiguo territorio mapuche y rearticularlo en una nueva lógica territorial. En otras palabras, se buscó terminar con el territorio de la Araucanía y construir el Sur de Chile (...) El Sur, como expresión de una nueva territorialidad fue desplazando o a lo menos superponiéndose a la Araucanía y en esta dinámica, se fue invisibilizando a los mapuches en tanto productores y productos de la antigua territorialidad" (Flores, 2013). La colonización - vía inmigrantes extranjeros - su principal mecanismo, que consistía en la redacción de decretos supremos mediante los cuales les eran entregadas grandes extensiones territoriales a colonos extranjeros con el compromiso de radicar un número determinado de familias.

En la Figura 3, se presenta el mapa de la Región de La Araucanía a finales del siglo XIX, periodo donde se consolida la ocupación del Estado de los territorios fronterizos, sin embargo, la consolidación de la presencia del Estado es aún incipiente, tal como lo 
observaremos en los relatos de los viajeros que se presentan más adelante. En tanto, en la Figura 4 se muestra el mapa político-administrativo de área de estudio al año 1937. Como se puede apreciar, a esta época el Estado ya ha definido una estructura espacial administrativa, dando paso a su coporalización territorial.

\section{Figura 3 \\ MAPA DE LA PROVINCIA DE CAUTÍN EN 1897}

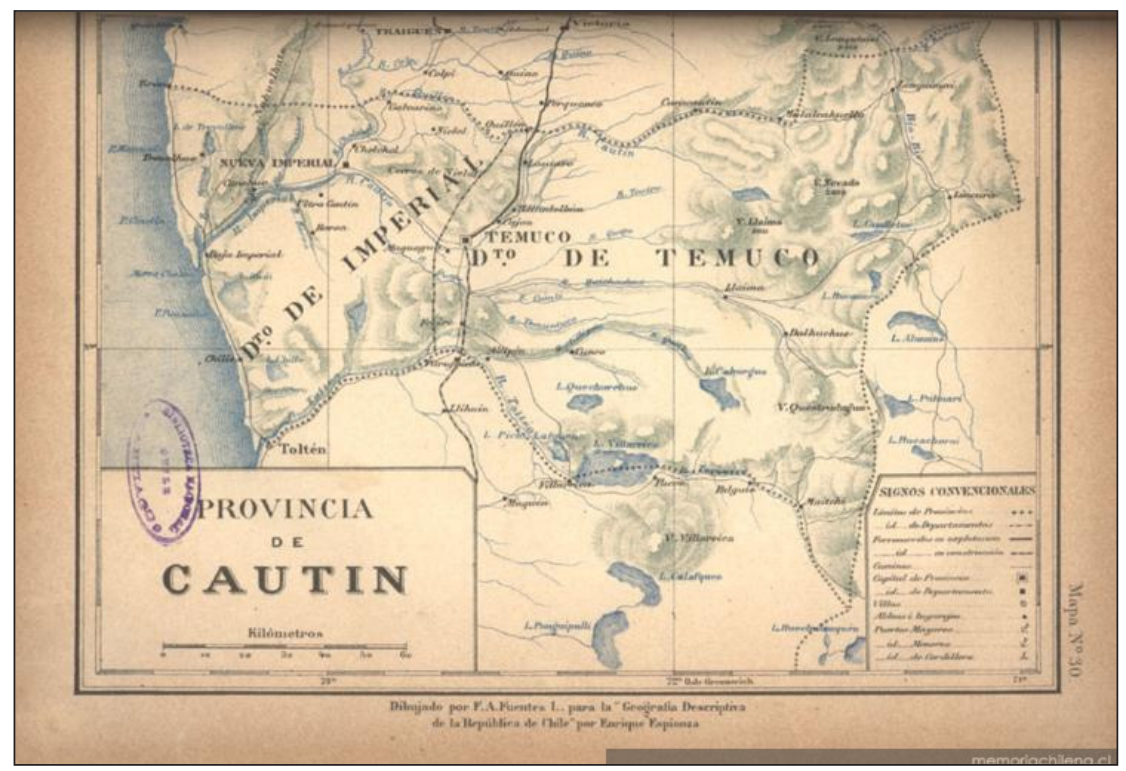

Fuente: Espinoza, 1897. Disponible en www.memoriachilena.cl

Esta es la base fundamental para la turistificación del territorio en la primera mitad del siglo XX, a partir del rol de Estado en la ocupación, militarización y construcción de un imaginario espacial de este territorio, mediante prácticas simbólicas de "invención" del lugar, vinculado a la representación e identificación de atractivos y sus formas de divulgación. Ejemplo de ello es la "Revista en Viaje" de Ferrocarriles del Estado (Flores, 2012), y de un conjunto de prácticas materiales, asociadas a la creación de infraestructuras, accesibilidad y equipamiento, como la construcción de hoteles (Gran Hotel Pucón y El Hotel de Puerto Varas). Por lo tanto, la producción material del espacio se vincula fundamentalmente, en el caso turístico, al anclaje espacial de infraestructuras, equipamiento y conectividad. Por infraestructuras nos referimos a aquellas asociadas a la generación de conectividad espacial, fundamentalmente a líneas férreas, carreteras y aeroportuarias, la construcción de hoteles y hosterías para el alojamiento de turistas y veraneantes, junto a establecimientos gastronómicos y de prácticas deportivas y recreativas (Martínez, 2014). 


\section{Figura 4 \\ MAPA POLÍTICO-ADMINISTRATIVO DE ÁREA DE ESTUDIO EN 1937}

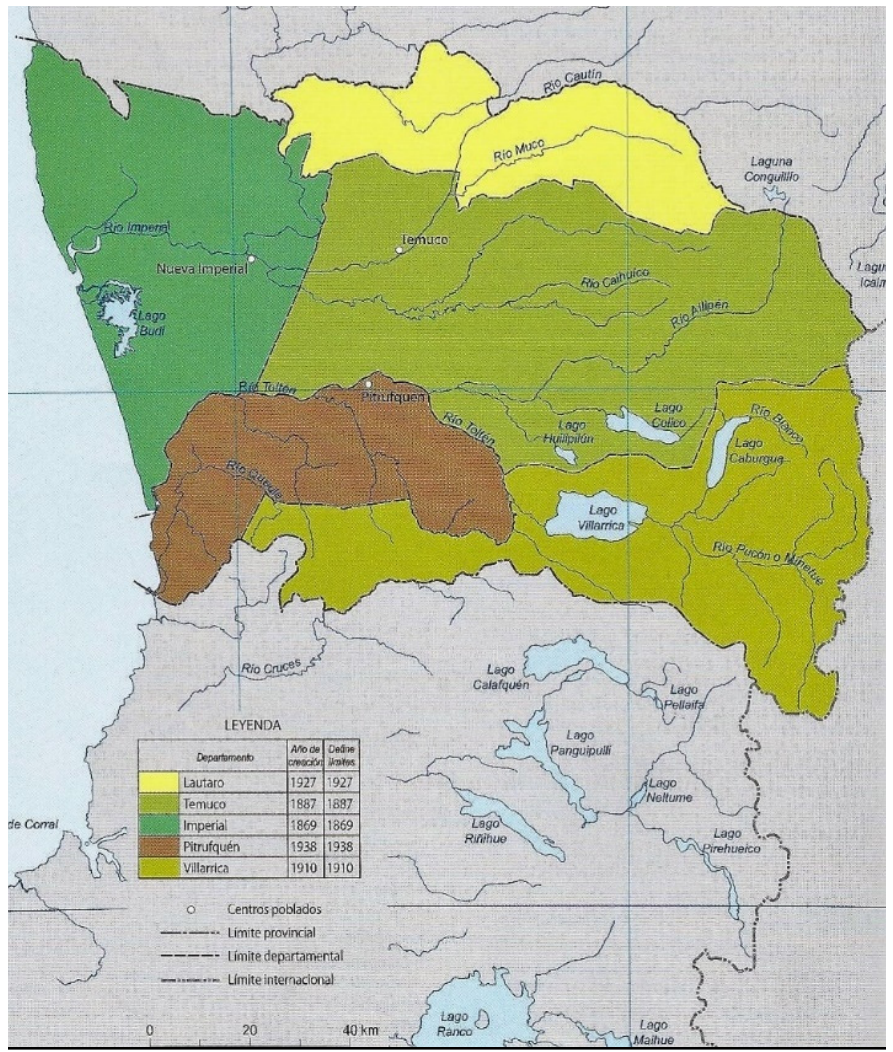

Fuente: Sagredo, González y Compan, 2016: 237.

\section{EL ESPACIO TURÍSTICO, EL CASO DE LA ARAUCANÍA ANDINO-LACUS- TRE, 1900-1940}

De acuerdo con lo señalado hasta aquí, podemos afirmar que los espacios turísticos se encuentran en un constante proceso de producción, proceso que puede ser reconocido mediante la identificación de sus sendas espacio-temporales. En ellas podemos reconocer su dimensión material y simbólica. Para el caso de la Araucanía andino-lacustre se han seleccionado dos eventos que marcan este proceso de producción de espacios turísticos, en primer lugar, abordaremos el caso de Juan Alfonso (1900), el primer viaje documentado hasta la fecha con motivos turísticos y la política del Estado en la construcción de infraestructuras y equipamiento para el desarrollo del turismo en Chile y particularmente en la Araucanía. 


\subsection{Los viajeros a la Araucanía. El caso de Juan Alfonso, 1900}

La práctica del turismo se consuma mediante la experiencia o vivencia que el turista realiza en un espacio turístico determinado, dicho fenómeno lo denominaremos como el "hecho turístico". Éste es además un evento, toda vez que es la cristalización espacio-temporal de la movilidad, el deseo de experienciar lugares diferentes a los habituales, basados en una expectativa, una preconcepción imaginaria del lugar a visitar, pero también, las formas como se transmiten y recrean dichos imaginarios por el turista.

De las diversas clasificaciones de turistas, se distingue aquella que diferencia al viajero del veraneante, lo cual es aplicable a los que visitaron la Araucanía en la primera mitad del siglo XX. En efecto, según Iribas (2003): "El veraneante fue aquel individuo que se tomaba un tiempo de ocio para recuperarse del trabajo, a través de su traslado a zonas balnearias, ya sea playas, termas o lagos, con el fin de asentarse por un tiempo largo con el pretexto de mejorar la salud. El viajero en cambio realizaba un viaje de carácter instructivo y de aproximación a espacios folclóricos, permaneciendo poco tiempo en cada lugar" (Citado por Cortés, 2014: 38).

En relación a los viajeros, el caso de José Alfonso (1900) es altamente valioso de destacar, en primer lugar, por ser el primer registro testimonial de un viajero a la Araucanía con motivaciones turísticas (el viaje se realizó en 1899), en segundo lugar, porque representa el perfil típico del viajero de principios de siglo, perteneciente a la elite aristocrática e intelectual y en tercer lugar, porque dichas motivaciones son estrictamente recreacionales, diferenciándose por lo tanto de otros viajeros que penetraron el sur movidos por el objetivo militar, de ocupación, reconocimiento del territorio o económico, como son los casos de Paul Treutler (1882), "Las andanzas de un alemán en Chile", quien registra su recorrido por el país en busca de yacimientos mineros, inspirado por un espíritu aventurero. También destacan Francis Drake, Thomas Cavendish, Charles Darwin y Diego Barros Arana, todos durante el siglo XIX.

Sin embargo, el relato de José Alfonso es particular ya que retrata el recorrido de siete viajeros desde Santiago a Valdivia, entre enero y marzo de 1899. El grupo estaba integrado por José Alfonso (político y jurista), Francisco Langlois (Jurista), Jorge Enrique Schneider (primer rector Liceo Aplicación de Santiago), Adolfo Page, Roberto Pinto y los hermanos Carlos y Otto Schleyer que se integran en Pitrufquén (hijos de un hacendado de la zona).

En su relato sobre su recorrido desde Pitrufquén a Villarrica destacan:

"I, a medida que avanzábamos, nuestra admiración iba en aumento. Atravesábamos la apretada i misteriosa selva araucana, de los grandes árboles $i$ de los grandes históricos recuerdos. La exclamación de icuán hermoso! Se escapaba a cada momento involuntariamente de nuestros labios i del fondo de nuestras almas. Conocíamos ya la montaña chilena por haber atravesado a caballo en años anteriores la que entonces en buena parte se estendia entre Valdivia i Puerto Montt, pero nada comparable con la que ese día cruzábamos admirados. En ese bosque inmenso no hai mas terreno labrado que la estrechísima senda que recorríamos i que conduce a Villarrica. A cada lado puede decirse que existe un verdadero muro formado por los seculares troncos i por tupidísima vegetación, hasta el punto de construir un conjunto absolutamente impenetrable para el hombre i para el animal” (Alfonso, 1900: 8) 
Destaca en este párrafo, el carácter autónomo del viaje, el espíritu aventurero de sus protagonistas y lo que Rodrigo Booth ha denominado "el descubrimiento de una zona considerada como incivilizada" (Booth, 2010: 14). En el siguiente párrafo se puede observar más nítidamente la valoración que ellos hacen del paisaje que observan, destacando los elementos naturales y la "belleza" de éstos, como la vegetación y el lago Villarrica, pero también su conexión experiencial, sensorial y vivencial, al decir de Volo (2009) y Fuentes, et.al. (2015).

“Oimos, por fin, a las sies de la tarde, una exclamación partida de la cabeza de la comitiva, $i$ un instante despues divisábamos, por entre los árboles de la apretada selva, una inmensa sábana de agua, que hubiéramos creido el mar si no hubiéramos sabido donde nos encontrábamos. ¡Era la gran laguna de Villarrica!. Nos detuvimos un momento a contemplar ese cuadro magnífico de la naturaleza, envuelto en un aire tan absoluto de tranquilidad i de silencio que nos tocó el alma. Permanecimos, callados tambien, dominando ese vasto panorama, que evocaba súbitamente de nuevo, con un relieve inalterable de realidad, en medio de un silencio como de tumba, nuestras mas vivas impresiones i todos nuestros recuerdos de una época sangrienta” (Alfonso, 1900: 11)

También José Alfonso transmite en su relato su visión sobre la capacidad y calidad del incipiente alojamiento turístico en Villarrica.

"I para que todo por allá tenga cierto sello de curiosa originalidad, el viajero que entra a la casa u hotelito del señor Nass se encuentra, de manos a boca, con el siguiente aviso, a modo de previa notificación, i que transcribimos fielmente, con todos sus pelos i señales: Aviso: - No se recibirá ningun alojado por menos de tres pesos i mas tambien se cobrará segun las circunstancias de las personas. Se advierte a las personas que desean alojar en este negocio privado que yo solamente recibiré personas mui distinguidas, formales i de buenas costumbres" (Alfonso, 1900: 12)

No es extraño el anuncio del señor Nass, por cuanto la presencia del Estado, aunque ya había ocupado militarmente la Araucanía, fundado fuertes y luego ciudades, tenía una precaria presencia policial y judicial a principios de 1900. Esto se pude corroborar en el texto de Enrique Espinoza "Jeografia Descriptiva de la República de Chile” (1897: 419), quien destaca que Villarrica había sido refundada en 1883 y que contaba con 166 habitantes.

Los viajeros constituyeron un vehículo para comunicar una serie de representaciones sobre el territorio fronterizo de la Araucanía, por ello, el presente trabajo buscó interrogar los conceptos de viaje y viajeros durante el siglo XIX, sus representaciones espaciales y cómo contribuyeron a impulsar un imaginario que avanzó desde la concepción de lo indómito, salvaje, inexplorado e incivilizado a propiciar la ocupación militar y alimentar el deseo de conocerla turísticamente.

\subsection{El rol del Estado: ocupación, ferrocarriles y hoteles}

La producción material del espacio se vincula fundamentalmente, en el caso turístico, al anclaje espacial de infraestructuras, equipamiento y conectividad. Por infraestructuras nos referimos a aquellas asociadas a la generación de conectividad espacial, fundamentalmente a líneas férreas, carreteras y aeroportuarias, la construcción de hoteles y hosterías para el alojamiento de turistas y veraneantes, junto a establecimientos gastronómicos y 
Figura 3

EL ROL DEL ESTADO EN DESARROLLO DEL TURISMO:

LA CONSTRUCCIÓN DE HOTELES

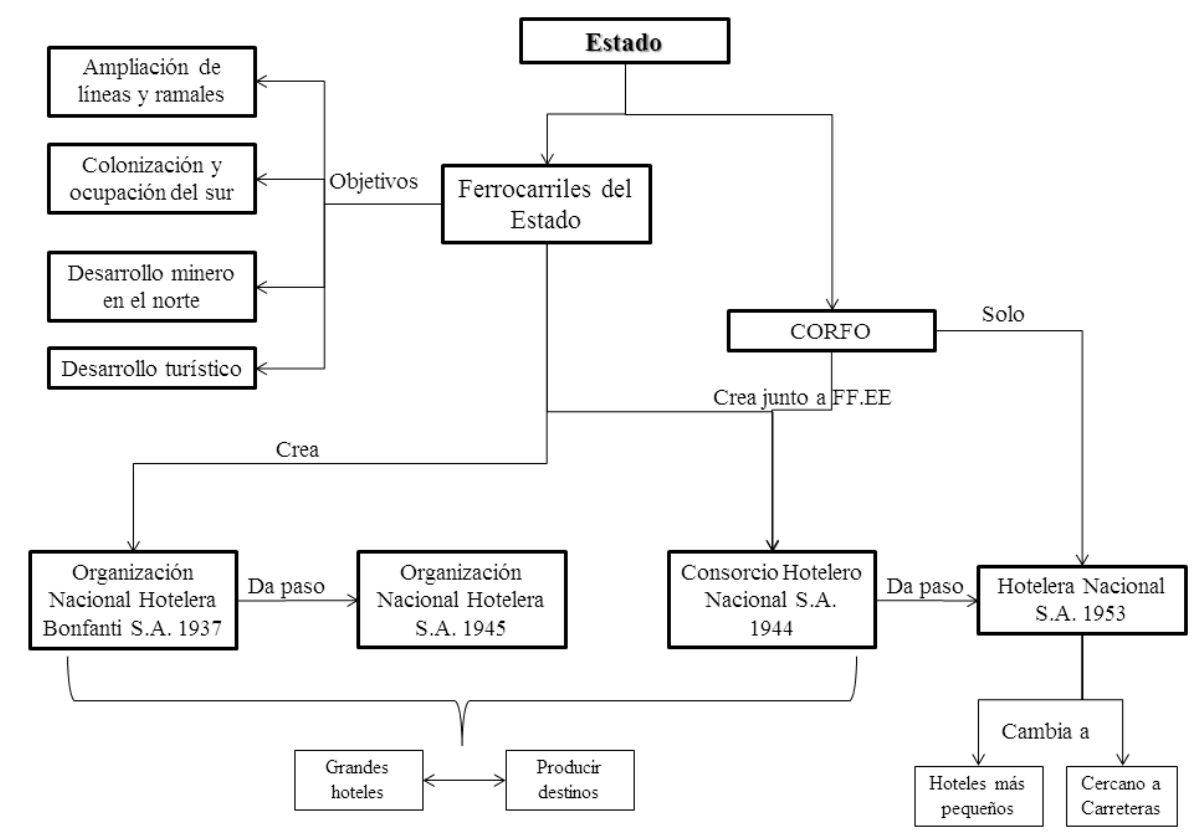

Fuente: Elaboración propia en base a Cortés (2014)

de prácticas deportivas y recreativas. Tal como ha sido constatado por Cortés (2014), Martínez (2014), Booth y Lavín (2013), Galeno-Ibaceta (2012), Booth (2010), el Estado ocupó un rol central el proceso de turistificación del territorio, tanto del sur, como del norte de Chile.

En la Figura 3 se presenta el rol del Estado en desarrollo del turismo, el cual se enmarcaba en procesos asociados a la ocupación y dominio territorial del sur, el desarrollo minero del norte, lo cual fue llevado a cabo, entre otros dispositivos, por la ampliación de las líneas férreas. En este sentido, el ferrocarril, a través de Ferrocarriles del Estado asumió la tarea, no solo de penetración y dominio territorial, mediante la construcción de hoteles, a través de la creación de empresas destinadas para ello (Tabla 2), sino que también la promoción de éstos a través del uso de estrategias de comunicación, como la Revista del Veraneante y la Revista en Viaje (Cortés, 2014 y Booth, 2010).

La ampliación del ferrocarril, en especial hacia el sur, junto con significar la dominación del espacio fronterizo por parte del Estado, de acuerdo con Cortés, implicó también una especie "colonización turística" del territorio (Cortés, 2014: 23), al propiciar la movilidad de nuevos viajeros (los turistas) y generar las condiciones de establecimiento en el lugar (los hoteles). En esa misma postura, Rodrigo Booth señala: "El desarrollo de los 
sistemas tecnológicos que permitieron la movilidad estacional de la población, sobre todo a partir del establecimiento de los sistemas de ferrocarriles en la zona central a partir de la década de 1860 y su extensión hacia el sur en la segunda década del siglo XX, garantizó una inédita disponibilidad de destinos de interés turístico en el país" (Booth, 2010: 12). De esta manera se configura la base fundamental para la turistificación del territorio en la primera mitad del siglo XX, a partir del rol de Estado en la ocupación, militarización y a la construcción de un imaginario espacial de este territorio, mediante prácticas materiales de "invención" del lugar, vinculado a la construcción de vías de comunicación y equipamiento y la representación e identificación de atractivos y sus formas de divulgación, como la Revista del Veraneante y la Revista en Viaje (Flores, 2012).

Asimismo, la participación de la empresa de Ferrocarriles del Estado en la construcción de hoteles se desarrolló a mediante su concurso en diversas empresas dedicadas a ello (Figura 3), donde se destaca una lógica de construcción de hoteles de gran tamaño, su localización en áreas urbanas y naturales, con el objetivo de generar una dinámica productiva vinculada al turismo, hasta que la Corporación de Fomento (CORFO) dependiente también del Estado, toma el control exclusivo del desarrollo y promoción de éste, modificando los criterios de construcción y localización, cambiando la escala del diseño arquitectónico y acercándose a la vías carreteras, por sobre las vías férreas (ver Figuras 4 y 5) (Cortés, 2014).

\section{Tabla 2 \\ LA CONSTRUCCIÓN DE HOTELES Y HOSTERÍAS POR PARTE DEL ESTADO}

\begin{tabular}{|l|l|l|l|}
\hline Organización & Hotel & Lugar & Año \\
\hline \multirow{4}{*}{$\begin{array}{l}\text { Organización Nacional } \\
\text { Hotelera Bonfanti S.A. }\end{array}$} & Gran Hotel Pucón & Pucón & 1935 \\
\cline { 2 - 4 } & Hotel Puerto Varas & Puerto Varas & 1936 \\
\cline { 2 - 4 } & Hostería Tejas Verdes & Llo Lleo & 1937 \\
\hline \multirow{4}{*}{$\begin{array}{l}\text { Organización Nacional } \\
\text { Hotelera S.A. }\end{array}$} & Hotel Pedro de Valdivia & Valdivia & 1952 \\
\cline { 2 - 3 } & Hotel City & Concepción & 1945 \\
\cline { 2 - 3 } & Gran Hotel Chillán & Chillan & $1945-1950$ \\
\cline { 2 - 3 } & Hotel Capri & Santiago & $1945-1950$ \\
\cline { 2 - 3 } & Hotel Pacífico & Arica & 1946 \\
\hline \multirow{4}{*}{$\begin{array}{l}\text { Consorcio Hotelero de } \\
\text { Chile S.A. }\end{array}$} & Hotel Turismo & Ovalle & \multirow{2}{*}{$1944-1950$} \\
\cline { 2 - 3 } & Hotel Turismo Prat & Iquique & \\
\cline { 2 - 3 } & $\begin{array}{l}\text { Hotel Turismo Francisco de } \\
\text { Aguirre }\end{array}$ & La Serena & \\
\cline { 2 - 3 } & Gran Hotel Turismo & Antofagasta & \multirow{2}{*}{} \\
\cline { 2 - 3 } & $\begin{array}{l}\text { Balneario Casino de } \\
\text { Peñuelas }\end{array}$ & La Serena & \\
\hline
\end{tabular}




\begin{tabular}{|l|l|l|l|}
\hline Organización & Hotel & Lugar & Año \\
\hline $\begin{array}{l}\text { Consorcio Hotelero de } \\
\text { Chile S.A. }\end{array}$ & $\begin{array}{l}\text { Yachting Club de la } \\
\text { Herradura }\end{array}$ & Coquimbo & $1944-1950$ \\
\hline \multirow{3}{*}{ Hotelera Nacional S.A. } & Hotel Antumalal & Pucón & 1950 \\
\cline { 2 - 4 } & Hostería & Chañaral & 1960 \\
\cline { 2 - 4 } & Hostería & Castro & 1962 \\
\cline { 2 - 4 } & Hostería & Ancud & 1962 \\
\hline
\end{tabular}

Fuente: Elaboración propia en base a Cortés (2014).

El esfuerzo por el desarrollo del turismo Chile y particularmente en la Araucanía se enmarca en los procesos modernizadores del Estado, asociados al control y dominación de nuevos espacios, su inserción en circuitos nacionales y mundiales de circulación de mercancías y la generación de nuevos significados para estos espacios incorporados al territorio nacional. Así, la "chilenización de los territorios fronterizos" (Flores, 2013: 443), mediante la creación de parques nacionales, junto con esta política de construcción de hoteles, contribuyeron a la turistificación del espacio, transformando el imaginario de la "selva araucana" (Booth, 2010: 23), por uno moderno, conectado, sin violencia, prístino, único y asociado a las motivaciones de viajeros y turistas.

\section{CONCLUSIONES}

La producción de espacios turísticos es una dinámica constante y en permanente evolución que se identifican en sendas espacio-temporales, las cuales dejan impresa una huella en el territorio. Estas sendas, son trayectorias que recorren los espacios, desde su condición de espacio geográfico a espacio turístico. Nos referimos, por lo tanto, no sólo a los atractivos y destinos turísticos, sino a una configuración compleja multiescalar del espacio, donde las formas de apropiación, ya sea simbólica o utilitaria, se encuentran en constante situación de interdependencia no excluyente.

Así, por una parte, se puede identificar en estos trayectos, el rol que ocuparon los primeros viajeros, en torno modificar el imaginario preexistente en la Araucanía, por uno asociado al discurso modernizador de principios del siglo XX, junto con el rol del Estado chileno en ocupar, dominar e integrar este territorio a circuitos globales de intercambio, no sólo ganadero, agrícola o forestal, sino que también turístico.

Se debe observar cómo el turismo, y el rol del ocio en las sociedades modernas, influyen en las configuraciones materiales e inmateriales de los territorios en una perspectiva espacio-temporal. En efecto, unido a los procesos de reestructuración territorial del Estado en el marco de la globalización económica, junto a un continuo proceso de privatización de paisajes naturales y la constitución de la Araucanía andino-lacustre, como punto de atracción para nuevos habitantes (Hidalgo y Zunino, 2011), reafirmar la noción de trayectorias o sendas en constante evolución, que identifican una rearticulación de este espacio y el ingreso de nuevos y diversos actores sociales, como los empresarios inmobiliarios; los tour operadores, los prestadores de servicios turísticos; la nueva ins- 
titucionalidad pública orientada al turismo, los cuales buscan articular el espacio local a las dinámicas de flujos de turistas del mercado nacional o global.

De esta manera, se busca superar la noción de "destino" o de "atractivo" que ha prevalecido en los estudios geográficos del turismo, por ejemplo en los trabajos acerca de los ciclos de vida de los destinos turísticos, por ello que planteamos el concepto de sendas espacio-temporales, la que se origina a partir de los trabajos de Hägerstrand y que avanza desde la particularidad del sujeto, al espacio turístico, entiéndelo como un producto social, flexible, plástico, móvil y no separado del tiempo histórico.

\section{REFERENCIAS BIBLIOGRÁFICAS}

ALFONSO, J. (1900): Un viaje a Valdivia. La civilización alemana en Chile. Imprenta Moderna. Santiago, Chile. Disponible en: http://www.memoriachilena.cl/602/w3-article-7826.html

BERDOULAY, V. (2012): "El sujeto, el lugar y la mediación del imaginario". En Lindón, A. y Hiernaux, D. (Dir.), Geografías de lo imaginario. Anthropos Editorial, Universidad Autónoma Metropolitana, México. pp. 49-65.

BOOTH, R. (2010): "El paisaje aquí tiene un encanto fresco y poético". Las bellezas del sur de Chile y la construcción de la nación turística". Hib: Revista de Historia Iberoamericana, vol. 3 (1), pp.10-32.

BOOTH, R. y LAVÍN, C. (2013): “Un hotel para contener el sur”. ARQ, no 83, pp. 56-61. BOULLON, R. (1991). Planificación del Espacio Turístico. México, Trillas.

BRAUDEL, F. (1968). La historia y las ciencias sociales. Madrid, Alianza Editorial.

CORTÉS, M. (2014). Turismo y arquitectura moderna en Chile. Guías y revistas en la construcción de destinos turísticos (1933-1962). ARQ Ediciones. Pontificia Universidad Católica de Chile.

ELDEN, S. (2004). Between Marx and Heidegger: politics, philosophy and Lefebvre's The production of space. Antipode, 36(1), pp. 86-105.

ESPINOZA, E. (1897). Jeografia Descriptiva de la República de Chile. Imprenta i encuadernación Barcelona. Santiago, Chile. Disponible en: http://www.memoriachilena. $\mathrm{cl} / 602 / \mathrm{w} 3$-article-3436.html

FLORES, J. (2012). La Araucanía y la construcción del sur de Chile, 1880-1950. Turismo y vías de transporte. Scripta Nova, Revista Electrónica de Geografía y Ciencias Sociales. Universidad de Barcelona. Vol. XVI, 418 (12).

FLORES, J. (2013): "La construcción del espacio. Una mirada histórica al territorio cordillerano de la Araucanía. El territorio andino de la Araucanía, concepto y antecedentes". En Núñez, A., Sánchez, R. y Arenas, F. Fronteras en movimiento e imaginarios geográficos. La Cordillera de los Andes como espacialidad sociocultural. Ril editores. Serie Geolibros, Pontificia Universidad Católica de Chile, Chile. pp. 415-449.

FUENTES, R., MORENO-GIL, S., GONZÁLEZ, C. y RITCHIE, B. (2015): “La creación y promoción de experiencias en un destino turístico. Un análisis de la investigación y necesidades de actuación", Cuadernos de Turismo, n ${ }^{\circ} 35$, pp. 71-94. 
GALENO-IBACETA, C. (2012): "The "Hotelera Nacional de Chile" (HONSA): modern tourism in the desert territory in northern Chile. In Conference of the International Forum on Urbanism. International Forum on Urbanism.

GIBSON, CH. (2008): "Locating geographies of tourism". Progress in Human Geography, vol. 32, pp. 407-422.

GIMÉNEZ, G. (1996): Territorio y cultura. Estudio sobre culturas contemporáneas. Universidad de Colima, México. pp. 9-30.

GIMÉNEZ, G. (2001): “Cultura, territorio y migraciones. Aproximaciones teóricas". Alteridades, vol. 11 (22). México. pp. 5-14

GONZÁLEZ, R. y MANTECÓN TERÁN, A. (2014): “Turismo y negocio inmobiliario: la crisis de un modelo de desarrollo. Tres estudios de casos de Canadá, Argentina y España”. Revista Estudios y Perspectiva en Turismo, vol. 23, pp. 685-705.

GRINBERGER, A.Y., SHOVAL, N. Y MCKERCHER, B. (2014): “Typologies of tourists' time-space consumption: a new approach using GPS data and GIS tools". Tourism Geographies, vol. 16 (1), pp. 105-123,

HÄGERSTRAND, T. (1970): “What about people in regional science?" Papers in Regional Science, vol. 24 (1), pp. 7-24.

HALL, C. M. (2011): "Publish and perish? Bibliometric analysis, journal ranking and the assessment of research quality in tourism". Tourism Management, vol. 32 (1), pp. 16-27.

HALL, C.M. (2005): “Time, space, tourism and social physics". Tourism Recreation Research, vol. 30 (1), pp. 93-8.

HARVEY, D. (1990): Los límites del capitalismo y la teoría marxista. México, Fondo de Cultura Económica.

HARVEY, D. (2004): La condición de la posmodernidad. Investigación sobre los orígenes del cambio cultural. Primera edición, primera reimpresión. Buenos Aires, Amorrouto editores.

HARVEY, D. (2007a): Urbanismo y desigualdad social. Séptima edición. Editorial Siglo XXI. Madrid, España.

HARVEY, D. (2007b): Espacios de esperanza. Ediciones Akal. España.

HIDALGO, R. y ZUNINO, H.M. (2011): "Negocios inmobiliarios en centros turísticos de montaña y nuevos modos de vida. El papel de los migrantes de amenidad existenciales en la Comuna de Pucón - Chile". Revista Estudios y Perspectivas en Turismo, Vol. 20. pp. 307-326.

HIERNAUX, D. (1999): "La fuerza de lo efímero. Apuntes sobre la construcción de la vida cotidiana en el turismo". En: Lindón, A. (coord.) La vida cotidiana y su espaciotemporalidad. Anthropos, Madrid-México. pp 95-122.

HIERNAUX, D. (2002): “Turismo e imaginarios". En: Hiernaux, D. y L. Van Duynen (Eds.), Imaginarios Sociales y Turismo Sostenible. San José, FLACSO. pp. 7-36

HIERNAUX, D. (2008): "El giro cultural y las nuevas interpretaciones geográficas del turismo”. GEOUSP. Espacio-Tempo, Sao Paulo, N²3. 177-187.

HIERNAUX, D. (2015): "Fantasías, sueños e imaginarios del turismo contemporáneo". En Hiernaux, D. (Coord.). Turismo, Sociedad y Territorio: una lectura crítica. Libro Homenaje a Manuel Rodríguez. Woog (1957-2015). Universidad Autónoma de Querétaro. México. 65-96. 
HIERNAUX, N. y LINDON, A. (1993): "El concepto de espacio y el análisis regional". Secuencia, $\mathrm{n}^{\circ} 25$, pp. 89-110.

IOANNIDES, D., HALKIER, H., y LEW, A.A. (2014): "Special issue introduction: evolutionary economic geography and the economies of tourism destinations". Tourism Geographies, 16 (4), pp. 535-539.

JIRÓN, P. y MANSILLA, P. (2013): “Atravesando la espesura de la ciudad: vida cotidiana y barreras de accesibilidad de los habitantes de la periferia urbana de Santiago de Chile". Revista de Geografía Norte Grande, n 56, pp. 53-74.

LEFEBVRE, H. (1974): "La producción del espacio". Papers: Revista de Sociología, no 3 , pp. 219-229.

LEFEBVRE, H. (2013): La Producción del Espacio. Madrid, Capitán Swing Libros.

LEITNER, H. (2008): "The politics of scale and networks of spatial connectivity: transnational interurban networks and the rescaling of political governance in Europe". En: Sheppard, E. y Mcmaster, R. B. (Eds.) (2008). Scale and geographic inquiry: Nature, society, and method. Blackwell Publishing Ltd. Australia.

LINDÓN, A. (2007): "El constructivismo geográfico y las aproximaciones cualitativas". Revista de Geografía Norte Grande, $\mathrm{n}^{\mathrm{0}} 37$, pp. 5-21

LINDÓN, A. (2010): “Los giros teóricos: texto y contexto". En: Lindón, A. y Hiernaux, D. Los giros de la Geografía Humana. Desafíos y horizontes. Barcelona, Anthropos Editorial, pp.

LINDON, A., HIERNAUX, D. y AGUILAR, M. (2006): "De la1 Espacialidad, el Lugar, y los Imaginarios Urbanos: a modo de Introducción. En: Lindón, A. et al. (Coord.) Lugares e Imaginarios en la Metrópolis. México, Anthropos, pp. 9-24.

LÓPEZ, Á. y MARÍN, G. (2010): "Turismo, capitalismo y producción de lo exótico: una perspectiva crítica para el estudio de la mercantilización del espacio y la cultura". Relaciones (Zamora), vol. 31 (123), 219-260.

MARTÍN, F. (2012): “Turismo y culturas originarias en América Latina". Avá. Revista de Antropología, $\mathrm{n}^{\circ} 20$.

MARTÍNEZ,P. (2014): "La construcción social de los territorios turísticos. El caso de Pucón en la región de la Araucanía, Chile”. Revista Geográfica del Sur, vol. 5 (7), pp. 63-76.

MASSEY, D. (2012): "Espacio tiempo y responsabilidad política en una era de desigualdad global”. En Albet, A. y Benach, N. (2012), Doreen Massey. Un sentido global del lugar. Barcelona, Editorial Icaria.

MASSEY, D. (2012b): "Imaginar la globalización: las geometrías del poder del tiempoespacio”. En: Albet, A. y N. Benach (2012), Doreen Massey. Un sentido global del lugar. Editorial Icaria, Barcelona.

MUÑOZ, F. (2006): El tiempo del territorio, los territorios del tiempo. En: Nogue, J. y Romero, J. Las otras geografías. Tirant lo Blanch. España.

NOGUÉS-PEDREGAL, A. (2012): "El cronotopo del turismo: espacios y ritmos". Revista de Antropología Social, 21, pp. 147-171.

PIANESI, F. y VARZI, A. (2000): "Events and event talk: An introduction". En Speaking of Events, J. Higginbottom, F. Pianesi and A. Varzi (Eds.), pp. 3-48.

PINASSI, A. (2015): "Espacio vivido: Análisis del concepto y vínculo con la Geografía del Turismo". Geographos. Revista digital para estudiantes de Geografía y Ciencias Sociales. Universidad de Alicante, vol. 6 (78), pp. 135-150. 
PINASSI, A. y ERCOLANI, P. (2017): “Turismo y espacio turístico: un análisis teórico conceptual desde la ciencia Geográfica”. Anais Brasileiros de Estudios Turísticos./ ABET, Juiz de Fora, 7 (1), pp. 42-61.

PINASSI, A. y ERCOLANI, P. (2015): "Geografía del turismo: análisis de las publicaciones científicas en revistas turísticas. El caso de Argentina". Cuadernos de Geografía: Revista Colombiana de Geografía, vol. 24 (1), pp. 213-230.

RODRÍGUEZ, S. (2015): “Geografía cotidiana y prácticas culturales: construcción simbólica de los patios del Cementerio General de Santiago". Revista de Historia y Geografía, Universidad Católica Silva Henríquez, nº 32. pp. 117-130.

SAGREDO, R., GONZÁLEZ, I. y COMPAN, J. (2016): La política en el espacio. Atlas histórico de las divisiones político-administrativas de Chile. Instituto Geográfico Militar, Pontificia Universidad Católica de Chile y Dirección de Bibliotecas, Archivos y Museos. Santiago de Chile.

BLAZQUEZ SALOM, M. y MURRAY, I. (2010): "Una geohistoria de la turistización de las islas Baleares". El Periplo Sustentable: revista de turismo, desarrollo y competitividad, no 18 , pp. 69-118.

SANTANA, A. (2008): Antropología y turismo. Editorial Ariel. España.

SANTOS, M. (1996a): De la totalidad al lugar. Oikos-tau. Barcelona, España.

SANTOS, M. (1996b): Metamorfosis del espacio habitado. Oikos-tau. Barcelona, España.

SANTOS, M. (2000): La naturaleza del espacio. Técnica y tiempo. Razón y emoción. Editorial Ariel. Barcelona, España.

SILVEIRA, M.L. (2009): "Región y división territorial del trabajo: desafíos en el período de la globalización”. Investigación y Desarrollo, vol. 17 (2), pp. 434-455.

SILVEIRA, M.L. (2010): "Nuevo orden espacial de la globalización: encrucijadas y horizontes". Revista Geográfica Espacios, Universidad Academia de Humanismo Cristiano, Santiago, Chile.1, pp. 1-17.

SILVEIRA, M.L. (2013): "Tiempo y espacio en la geografía: dilemas y reflexiones. Revista de Geografía Norte Grande, $\mathrm{n}^{\circ}$ 54, pp. 9-29.

SOJA, E. (2010): Tercer espacio: extendiendo el alcance de la imaginación geográfica. En: Benach, N. y Albet, A.: Edward W. Soja. La perspectiva postmoderna de un geógrafo radical. Icaria Editorial. Barcelona.

TREUTLER, P. (1882): Las andanzas de un alemán en Chile. 1851-1863. Editorial Pacífico S.A. Disponible en: http://www.memoriachilena.cl/602/w3-article-8041.html VALDÉS, F. (1996): "Pensar lo público", Fractal 1 (1), 161-178.

VILLARROEL, R. (2006): La naturaleza como texto. Hermenéutica y crisis medioambiental. Santiago de Chile, Editorial Universitaria.

VOLO, S. (2009): “Conceptualizing Experience: A Tourist Based Approach”. Journal of Hospitality Marketing \& Management, vol. 18 (2-3), pp. 111-126.

WORBOYS, M. (2005): "Event oriented approaches to geographic phenomena". International Journal of Geographical Information Science, vol. 19 (1), pp. 1-28.

ZUSMAN, P., HEVILLA, C. y MOLINA, M. (2006): “Geografía de los tiempos lentos”. En: Nogue, J. y Romero, J. Las otras geografías. Valencia, Tirant lo Blanch, pp. 255-268. 